\title{
First-line treatment of chronic lymphocytic leukemia: role of alemtuzumab
}

This article was published in the following Dove Press journal:

OncoTargets and Therapy

26 March 2010

Number of times this article has been viewed

\section{Carmen Diana Schweighofer ${ }^{\prime}$ Clemens-Martin Wendtner ${ }^{2}$ \\ 'Department of Hematopathology, The University of Texas M.D. Anderson Cancer Center, Houston, Texas, USA; ${ }^{2}$ Department of Internal Medicine I, University of Cologne, Cologne, Germany}

Correspondence: Carmen Diana

Schweighofer

Department of Hematopathology, The

University of Texas M.D. Anderson Cancer

Center 1515 Holcombe Blvd, Houston,

TX 77030, USA

Tel +l 7137924134

Fax + I 7137927273

Email carmen.schweighofer@uk-koeln.de, cdschweighofer@mdanderson.org

\begin{abstract}
The CD52-targeting antibody alemtuzumab is established in clinical practice with convincing activity in relapsed and refractory chronic lymphocytic leukemia (CLL), particularly in patients with high-risk features and adverse prognosis. In the CAM307 study alemtuzumab was tested and finally approved as a first-line single agent, even though the hurdle with chlorambucil as the contender was not set very high. Within clinical trials, the drug demonstrated an excellent ability to eliminate minimal residual disease in blood and bone marrow, which has been correlated with a corresponding survival advantage in patients. However, in the maintenance setting, infectious complications due to severe $\mathrm{T}$ cell suppression have been highlighted and do not allow clinicans to use alemtuzumab outside of clinical trials. This review discusses potential therapeutic niches and future applications of alemtuzumab with a focus on CLL front-line treatment.
\end{abstract}

Keywords: CLL, alemtuzumab, Campath, front-line, first-line treatment

\section{Management issues and current practices in treating B-CLL Introduction}

B cell chronic lymphocytic leukemia (CLL) is the most common leukemia in western countries with an incidence of 3 to 5 newly diagnosed patients, mostly elderly, per 100,000 annually. ${ }^{1}$ The clinical course and prognosis of CLL is fairly variable: some patients live an unaffected life with stable disease for years without intervention, others suffer an aggressive and wasting disease course with rapid progression, arduous treatments and advanced death. Hence, overall survival rates in CLL range from less than 2 to more than 15 years (median 9 years) after diagnosis, and almost one-third of patients die within 5 years after disease onset. ${ }^{1-3}$ Except for allogeneic stem cell transplantation applicable in a small proportion of patients, no curative treatment has been defined for the disease.

\section{Clinical and biological heterogeneity of CLL requires risk-adapted patient management in prospective clinical trials}

The early identification of patients at high risk of an unfavorable disease course and the right time and choice of therapy in this particular patient group are currently the most delicate and unsolved challenges in CLL treatment. 
The discovery of recurrent and prognostic relevant chromosomal aberrations in CLL cells via conventional cytogenetics and fluorescence in situ hybridization (FISH) has introduced the stratification of CLL cases according to the presence or absence of genomic key abnormalities. ${ }^{4,5}$ Deletions/mutations in chromosome $17 \mathrm{p} 13$, the site of the tumor suppressor TP53 (p53 gene), are associated with resistance or early failure after chemotherapy with or without the CD20-antibody rituximab and go along with the most decreased survival of patients. ${ }^{5-10}$ Once refractory to treatment based on purine analogues, such as fludarabine, patients belong to the worst prognostic category with a median overall survival of less than 12 months. ${ }^{11}$ Similarly, deletions/mutations in chromosome 11q22-23 (includes the $A T M$ gene locus) correlate with early advanced disease, particular in lymph nodes, shorter time to first treatment and shortened long-term survival after chemotherapy. ${ }^{4,5,12}$ Other powerful surrogate markers of an unfavorable prognosis are an unmutated status of the immunoglobulin heavy chain variable region genes (IGHV) and an elevated level of ZAP70 expression in CLL cells. ${ }^{13-15}$ The variety and variability of numerous other available biomarkers of prognosis reflect the clinical and biological heterogeneity of CLL. However, for many of these the final role for individual patient management and treatment decisions in clinical practice needs to be validated in prospective clinical trials.

\section{Front-line treatment in CLL: where do we stand?}

In general, "watchful waiting" with therapeutic action until the disease becomes symptomatic, or causes progressive bone marrow failure or systemic malaise, has been the gold standard in CLL. First-line drugs, approved by regulatory agencies include alkylating agents like chlorambucil, cyclophosphamide and bendamustine, the purine analog fludarabine and the monoclonal CD52-antibody alemtuzumab. Explicit approval of the CD20-antibody rituximab for combined immunochemotherapy in untreated CLL has been given by the European Medicines Agency (EMEA) in February 2009. A survival benefit for CLL patients treated at early stage of their disease has never been shown. However, this has been validated only for treatment with the alkylator chlorambuci $1^{16}$ and is currently subject of clinical trials applying newer therapeutic options (ie, purine analog based chemo- or immunochemotherapy).

Single agent therapy, including alemtuzumab, achieves limited rates of complete remissions $(<10 \%-24 \%)$ in CLL
(Table 1). In contrast, combination therapy based on purine analogues, such as fludarabine (F), has shifted the treatment paradigm of CLL front-line therapy from purely palliative treatment to treatment with intent to cure. According to a pivotal phase II trial at the M.D. Anderson Cancer Center (Texas, USA) and a randomized phase III study by the German CLL Study Group (GCLLSG), combined immunochemotherapy by fludarabine, cyclophosphamide and rituximab (FCR) is currently the most active front-line regimen and taking the lead as a standard in treatment-naïve patients with limited comorbidity: ${ }^{17-19}$ With an overall response rate (ORR) of 95\%, 44\% complete responders (CR) and progression-free survival (PFS) of 51.8 months, FCR was significantly better than the hitherto standard FC (ORR 88.4\%, CR 21.7\%, PFS 32.8 months) in the so far largest randomized trial on FCR with 817 recruited patients. ${ }^{17}$ Although this regimen induced significantly more myelosuppression than FC, particularly neutropenias, there was no proportional increase of infections. ${ }^{17-19}$ Major CLL study groups are now investigating modifications of the FCR regimen in order to optimize efficacy and decrease toxicity (ie, by dose reduction of FC, increased dose of rituximab, addition of mitoxantrone or alemtuzumab, replacement of the FC-"backbone" by bendamustine, for example). ${ }^{20-24}$

Despite the encouraging achievements by first-line immunochemotherapy, available long-term follow-up data of the M.D. Anderson trial suggest that the majority of patients responding to FCR still inevitably progress at a deferred time. ${ }^{18,19}$ In contrast to patients with $11 \mathrm{q}$ abnormalities, who seem to benefit particularly from FCR treatment, cases with an unmutated IGHV gene or 17p/TP53 abnormalities although they respond slightly better to FCR than to chemotherapy alone - continue to have an inferior response, PFS and overall survival (OS). ${ }^{19,25-27}$

\section{Elimination of minimal residual disease (MRD) increases the probability of long-term survival in CLL patients}

Two major mechanisms might account for treatmentrefractory disease: First, clonal selection of CLL cells harboring advantageous mutations or chromosomal deletions of tumor suppressors (such as TP53), second, clonal evolution of not thoroughly eradicated CLL cells surviving as MRD in physiologic niches. ${ }^{28-30}$ With the availability of standardized approaches for four-color flow cytometry ("MRD flow") and PCR-based amplification of the rearranged variable region of the IGHV gene rearrangements (using consensus or clone specific primers), one single residual CLL cell can currently be 
Table I Efficacy of alemtuzumab compared to other first-line single-agent regimens in chronic lymphocytic leukemia

\begin{tabular}{|c|c|c|c|c|c|c|c|c|c|}
\hline Drug & Author & $\begin{array}{l}\text { Trial } \\
\text { phase }\end{array}$ & $\begin{array}{l}\text { No. } \\
\text { of pts }\end{array}$ & Max dose & ORR (\%) ${ }^{a}$ & CR (\%) ${ }^{a}$ & $\begin{array}{l}\text { Median PFS } \\
\text { (months) }\end{array}$ & $\begin{array}{l}\text { Median OS } \\
\text { (months) }\end{array}$ & $\begin{array}{l}\% \text { OS at } \\
n \text { years }\end{array}$ \\
\hline Alemtuzumab iv & Hillmen et $\mathrm{al}^{59}$ & III & 149 & $\begin{array}{l}30 \mathrm{mg} \text { tiw iv, } \\
12 \text { weeks }\end{array}$ & 83 & 24 & 14.6 & $\mathrm{nr}$ & - \\
\hline \multirow[t]{2}{*}{ Alemtuzumab sc } & Lundin et $\mathrm{a}^{53}$ & ॥ & 41 & $\begin{array}{l}30 \text { mg tiw sc, } \\
18 \text { weeks }\end{array}$ & 87 & 19 & $\mathrm{nr}$ & $\mathrm{nr}$ & - \\
\hline & Karlsson et al ${ }^{66}$ & & & & & & $\begin{array}{l}14 \text { (TTP) } \\
28 \text { (TTTF) }\end{array}$ & - & - \\
\hline \multirow[t]{5}{*}{ Fludarabine iv } & Rai et $\mathrm{al}^{87}$ & III & 170 & $\begin{array}{l}25 \mathrm{mg} / \mathrm{m}^{2} \text { day } \\
\mathrm{I}-5, \mathrm{q} 28 \mathrm{~d}, 6 \text { cycles }\end{array}$ & 63 & 20 & 20 (TTP) & 66 & - \\
\hline & Eichhorst et al ${ }^{88 b}$ & III & 182 & $\begin{array}{l}25 \mathrm{mg} / \mathrm{m}^{2} \text { day } \\
\mathrm{I}-5, \mathrm{q} 28 \mathrm{~d}, 6 \text { cycles }\end{array}$ & 82.9 & $\begin{array}{l}6.7 \\
18.3 \mathrm{uCR}\end{array}$ & 20 & $\mathrm{nr}$ & $\begin{array}{l}80.7 \text { at } \\
3 \text { years }\end{array}$ \\
\hline & Catovsky et al ${ }^{9}$ & III & 181 & $\begin{array}{l}25 \mathrm{mg} / \mathrm{m}^{2} \text { day } \\
\mathrm{I}-5 \text { iv or } 40 \mathrm{mg} / \mathrm{m}^{2} \\
\text { day } \mathrm{I}-5 \mathrm{po}, \mathrm{q} 28 \mathrm{~d} \text {, } \\
6 \text { cycles }\end{array}$ & 80 & 15 & 23 & - & 52 at 5 years \\
\hline & Flinn et $\mathrm{al}^{89}$ & III & 137 & $\begin{array}{l}25 \mathrm{mg} / \mathrm{m}^{2} \text { day } \\
\mathrm{I}-5, \mathrm{q} 28 \mathrm{~d}, 6 \text { cycles }\end{array}$ & 59.5 & 4.6 & 19.2 & $\mathrm{nr}$ & 80 at 2 years \\
\hline & Eichhorst et al $\mathrm{a}^{38 c}$ & III & 87 & $\begin{array}{l}25 \mathrm{mg} / \mathrm{m}^{2} \text { day } \\
\mathrm{I}-5, \mathrm{q} 28 \mathrm{~d}, 6 \text { cycles }\end{array}$ & 72 & 7 & 19 & 46 & - \\
\hline Bendamustine iv & Knauf et $\mathrm{al}^{90}$ & III & 162 & $\begin{array}{l}100 \mathrm{mg} / \mathrm{m}^{2} \mathrm{dl}-2, \\
\mathrm{q} 28 \mathrm{~d}, 6 \text { cycles }\end{array}$ & 68 & 31 & 21.6 & - & - \\
\hline Cladribine iv & Robak et al ${ }^{91}$ & III & 126 & $\begin{array}{l}0.12 \mathrm{mg} / \mathrm{kg} \mathrm{dl}-5 \text {, } \\
\mathrm{q} 28 \mathrm{~d}, 6 \text { cycles }\end{array}$ & 78 & 21 & 23.5 & 51.2 & - \\
\hline \multirow[t]{6}{*}{ Chlorambucil po } & $\begin{array}{l}\text { Hillmen } \\
\text { et al }{ }^{59}\end{array}$ & III & 148 & $\begin{array}{l}40 \mathrm{mg} / \mathrm{m}^{2}, \mathrm{q} 28 \mathrm{~d} \\
12 \text { cycles }\end{array}$ & 55 & 2 & 11.7 & $\mathrm{nr}$ & - \\
\hline & Rai et $\mathrm{al}^{88}$ & III & 181 & $\begin{array}{l}40 \mathrm{mg} / \mathrm{m}^{2}, \mathrm{q} 28 \mathrm{~d}, \\
12 \text { cycles }\end{array}$ & 37 & 4 & 14 (TTP) & 56 & - \\
\hline & Robak et al ${ }^{92}$ & III & 103 & $\begin{array}{l}12 \mathrm{mg} / \mathrm{m}^{2} \mathrm{dl}-7, \\
6 \text { cycles }^{\mathrm{e}}\end{array}$ & 57 & 12 & 17 & 45 & \\
\hline & Catovsky et al ${ }^{9}$ & III & 324 & $\begin{array}{l}10 \mathrm{mg} / \mathrm{m}^{2} \mathrm{dl}-7 \\
12 \text { cycles }\end{array}$ & 72 & 7 & 20 & - & 59 at 5 years \\
\hline & Knauf et $\mathrm{al}^{90 \mathrm{~d}}$ & III & 157 & $\begin{array}{l}0.8 \mathrm{mg} / \mathrm{kg} \mathrm{dl}, \\
\mathrm{dl}+15,6 \text { cycles, }\end{array}$ & 31 & 2 & 8.3 & - & - \\
\hline & Eichhorst et al $\left.\right|^{38 c}$ & III & 98 & $\begin{array}{l}0.4 \mathrm{mg} / \mathrm{kg} \mathrm{dl}, \\
\mathrm{dl}+\mathrm{I}, \mathrm{I}, 2 \text { cycles, } \\
\text { dose increased by } \\
0.1 \mathrm{mg} / \mathrm{kg} \text { each } \\
\text { cycle up to } \\
0.8 \mathrm{mg} / \mathrm{kg}\end{array}$ & 51 & 0 & 18 & 64 & - \\
\hline Rituximab iv & Hainsworth et al ${ }^{93}$ & ॥ & 44 & $\begin{array}{l}375 \mathrm{mg} / \mathrm{m}^{2}, \\
\text { I } \times / \text { week, } 4 \text { weeks }\end{array}$ & 58 & 9 & 18.6 & - & - \\
\hline
\end{tabular}

a Response assessed according to NCIWorking Group Criteria 199694, binclusion limited to patients $\leq 65$ years of age, cinclusion limited to patients $>65$ years of age, ${ }^{\circledR}$ inclusion limited to patients $<75$ years of age, eadministered in conjunction with prednisone.

Abbreviations: d, day; CR, complete response. iv, intravenous. nr, not reached; ORR, overall response rate; OS, overall survival; PFS, progression-free survival; Pts, patients; q28d, administered every 28 days/4-weekly; sc, subcutaneous;TTP, time to progression;TTTF, time to treatment failure; uCR, unconfirmed CR.

tracked in $\leq 10,000$ to 100,000 leukocytes of peripheral blood or bone marrow. ${ }^{31-33}$ The achievement of a MRDnegative remission by flow has been correlated with improved progression-free and/or overall survival in several clinical trials. In an exemplar study by Moreton and colleagues, alemtuzumab was the first and only drug, which - given as a single agent - induced four-color flow-confirmed molecular remissions in correlation with an overall survival benefit in relapsed/refractory CLL patients (for details see below).$^{34}$ As a result of these and other studies, MRD negativity has been adopted as a recommended trial endpoint in the recently updated diagnostic and treatment guidelines of the IWCLL working group. ${ }^{35}$ 


\section{Future challenges in CLL front-line therapy}

In the front-line setting, the overall goal is to further develop treatment regimens, which are clinically safe but maximally eradicate detectable disease, including MRD. Future studies need to focus on the pre-emptive application of powerful new drugs and/or maintenance and consolidation strategies, particularly in young high-risk patients. The rapid lymphocyte depleting effect of alemtuzumab appears suitable to pursue these goals and will be discussed in this review. Moreover, considerable attention on patients with high-risk disease is required in upcoming front-line trials. ${ }^{19,36,37}$ The evidence of possible clonal outgrow of CLL cells with 17p-/TP53 abnormalities at relapse indicates that non-eradicating treatments might be potentially harmful in patients with up-front presence of subclonal $17 \mathrm{p}$-deletions or TP53 mutations. ${ }^{28-30}$ Increasing age and comorbidity is another future challenge to be solved: elderly and/or comorbid patients benefit less frequently from fludarabine-based chemotherapy or FCR than their younger counterparts with less comorbidity and need consideration in studies applying less aggressive treatment regimens..$^{17,19,38}$

\section{Mechanism of action, pharmacology/kinetics of alemtuzumab}

\section{Pharmacocharacteristics of alemtuzumab}

Alemtuzumab (CAMPATH-1H, Campath ${ }^{\circledR} /$ MabCampath $^{\circledR}$; Bayer Schering Pharma, Berlin) is a fully humanized IgG1-type monoclonal antibody directed against CD52, a glycosylphosphatidylinositol-anchored cell surface glycoprotein expressed on human B and T cells, natural killer cells, eosinophils and macrophages..$^{39,40}$

Originally, CAMPATH-1H was designed by Waldmann and colleagues for targeted depletion of normal $\mathrm{T}$ cells from donor bone marrow to combat graft-versus-host disease. ${ }^{41}$ The relatively high density of CD52 on cells from B and $\mathrm{T}$ cell derived lymphoproliferative disorders $(\sim 500,000$ antigen epitopes/cell) including CLL, attracted interest in the use of alemtuzumab as a cancer therapeutic. Normal hematopoietic stem cells, erythrocytes and platelets lack CD52 surface expression and are hence protected from drug-induced cytotoxicity. ${ }^{42,43}$ In contrast, neutrophils were recently reported to express low levels of CD52, which allow complement-mediated lysis and explain previously observed clinical neutropenias under alemtuzumab. ${ }^{44}$

The antibody kills target cells by complement- and/or antibody-dependent cellular cytotoxicity, but seems also to be capable of inducing direct apoptosis via caspase-dependent and -independent mechanisms. ${ }^{45-47}$

In vitro synergistic apoptotic effects of combined alemtuzumab plus rituximab or purine analogs have been correlated to complementary activities in the deregulation of pro- or anti-apoptotic molecules such as Bax, Bcl-2. ${ }^{46}$ Further, an increased surface expression of CD52 after rituximab treatment was observed to initiate alemtuzumab sensitivity in rituximabresistant cell lines. ${ }^{48}$ These observations suggest possible clinical benefits from the simultaneous or sequential application of alemtuzumab with these or related drugs in vivo.

Clinically, the antibody reduces normal lymphocytes of both B- and T-lineage, resulting in a profound and occasionally long-lasting lymphopenia with concomitant immunosuppression. This has been associated with an increased risk of opportunistic infections, particularly in heavily pretreated patients. Cytomegalovirus (CMV) reactivation is the most common of such events and requires careful monitoring of patients under alemtuzumab according to published guidelines. ${ }^{49}$ An anti-infective prophylaxis with cotrimoxazole and acyclovir or equivalent is mandatory during therapy and should be continued for at least 6 months after cessation of alemtuzumab. ${ }^{49}$

Alemtuzumab preferentially attacks CLL cells in peripheral blood, spleen and bone marrow, whereas bulky lymphadenopathy $(>5 \mathrm{~cm})$ is less affected. ${ }^{34,50,51}$ The rapid clearance of CLL cells from peripheral blood and bone marrow has been depicted as an "in vivo purging" effect ${ }^{52}$ and occurs after a median treatment time of 21 days. The terminal halflife of the antibody is estimated to be approximately 15 to 20 days. ${ }^{53-55}$ Serum antiglobulin responses to alemtuzumab have been rarely $(<1 \%)$ observed in patients who received the antibody first-line and subcutaneously. ${ }^{56,57}$

\section{Recommended dosing of alemtuzumab}

Different routes and schedules to administer alemtuzumab as monotherapy or as a combined regimen have been investigated. Usually, treatment protocols initiate dosing with a 3-day dose escalation starting from $3 \mathrm{mg}$ in order to attenuate first-dose reactions. Intravenous (iv) administration of alemtuzumab has been correlated with a higher rate of first-dose side effects (eg, "flu-like" symptoms, chills, rigor, hypotension, nausea, vomiting, rash, urticaria, bronchospasm) compared to subcutaneous (sc) application, which on the other hand entails more convenience and the possibility of self-administration in an outpatient setting..$^{50,53,58-60} \mathrm{~A}$ local injection-site erythema occurs frequently after sc application of alemtuzumab. This side effect is normally transient, 
and, if clinical tolerable, may delay but should not prevent continued sc treatment. Both, infusion and injection-site related side effects usually subside with repeated applications of alemtuzumab. ${ }^{50,53,58,61}$

Traditionally, a 12-week regimen with $30 \mathrm{mg}$ iv 3 times a week (tiw) has been most frequently used in CLL trials with alemtuzumab, but some studies have investigated other dose levels and treatment durations. The traditional schedule was designed to yield a cumulative dose around $1 \mathrm{~g}$, which resembles the approximate target dosage required to saturate all CD52-antigen binding sites in an average CLL patient. ${ }^{43,53}$ Treatment longer than 12 weeks has been correlated with enhanced clearance of CLL cells from bone marrow and improved responses, though trials comparing different schedules and concomitant toxicity of alemtuzumab are not available. ${ }^{53}$ Similarly, high maximum trough serum concentrations of the antibody, given tiw, have been associated with an improved clinical response and MRD reduction in bone marrow. ${ }^{56,62}$ Subcutaneous dosing is able to achieve blood concentrations comparable to those after iv infusion, but requires a longer time of drug accumulation and the application of a higher cumulative dose. ${ }^{56}$ However, if administered at $30 \mathrm{mg}$ tiw for 12 weeks, sc alemtuzumab has been demonstrated to be not only better tolerated, but as clinically effective as iv alemtuzumab. ${ }^{57}$ Therefore, sc dosing of the traditional 12-week regimen has become the most preferred and recommended route of alemtuzumab monotherapy. ${ }^{49,57}$ In case of good tolerability and efficacy, treatment duration might be extended for more than 12 weeks to achieve maximum response quality at the discretion of the treating physician. ${ }^{49}$

\section{Rationale for alemtuzumab: experience in previously treated CLL Alemtuzumab is the most active single agent in treatment refractory and high risk CLL}

Most available experience with alemtuzumab in CLL has been collected in the relapsed and/or refractory setting, but represents essential knowledge about clinical and pharmacodynamic/kinetic characteristics of the drug. One of the pivotal phase II trials attracting major attention to the efficacy of alemtuzumab was performed as salvage monotherapy in 93 CLL patients with inferior prognosis, who were refractory to fludarabine and had only few treatment options. ${ }^{11}$ After 12 weeks of $30 \mathrm{mg}$ alemtuzumab iv tiw, the ORR reached $33 \%$ with $2 \%$ complete and $31 \%$ partial remissions (PR). There was no difference in response between patients above or below the age of 70 (median age 66 , range $31-86$ ). The median time to progression (TTP) was 9.5 months for responders versus 4.7 months in all patients. Based on the results of this study, alemtuzumab acquired official approval in 2001 in the US and Europe for CLL patients, who were refractory to fludarabine or alkylating agents. Similar findings have recently been demonstrated by a German study (CLL2H, GCLLSG), applying the same dose schedule in 103 (109 patients enrolled) fludarabinerefractory patients (34\% ORR, 4\% CR, 30\% PR), however by a subcutaneous route of administration. ${ }^{57}$ Besides generally mild infusion or injection site related events, grade III/IV toxicity was comparable in these two trials and dominated by transient cytopenias (neutropenia, thrombopenia) in $>50 \%$ of patients and infections (including CMV reactivations) in at least $26 \%$ of patients. The latter were mostly reversible and occurred less frequently in responding versus nonresponding patients, which indicated an additional impact of disease-related immune dysfunction for these events. Based on the positive experience with sc alemtuzumab in CLL2H and other studies, a registration trial (CAM203) for the sc application of the antibody in previously treated CLL has been initiated.

Corresponding to its activity in fludarabine-refractory patients, early studies with alemtuzumab also demonstrated unexpected activity in patients with high-risk genetic features, particularly in chemotherapy-refractory patients presenting with $17 \mathrm{p}$-deletions by FISH or TP53 mutations. ${ }^{63,64}$ In this group ORR of $39 \%$ to $50 \%$ have been reported. The most comprehensive study on the efficacy of alemtuzumab monotherapy in different high-risk populations of treatment refractory high risk CLL patients was recently provided by Stilgenbauer and colleagues with the final report of the above-mentioned CLL2H trial: ${ }^{57}$ In their experience alemtuzumab was able to overcome the impact of several genetic factors of adverse prognosis, such as either unmutated IGHV, FISH positivity for $17 \mathrm{p}$-, 11q-deletion or trisomy 12 , or presence of TP53 mutations. ORR, median PFS (7.7 months) and OS (19.1 months) did not differ significantly in patients with or without any of these abnormalities. ORR and OS were only significantly decreased in elderly patients $>65$ years of age and patients with a lowered ECOG performance status.

Overall, published experience with alemtuzumab in relapsed CLL reveals unprecedented activity as a single-agent in both, refractory and high-risk patients. However, the reported number of achieved CRs is low and primarily accountable for 
yet unsatisfying levels of PFS and OS in these patients. To further increase the quality and duration of remissions, especially, for example, in patients with bulky lymphadenopathy, clinical studies are underway to explore the activity of alemtuzumab in combination with either chemotherapy, rituximab or high dose steroids in front-line and salvage treatment situations (see alemtuzumab combinations below).

\section{Alemtuzumab is capable of eradicating MRD and prolonging long-term outcome in CLL}

Due to its rapid lymphocyte depleting effect in peripheral blood and bone marrow alemtuzumab has been the most effective single drug for the elimination of MRD in CLL patients. Moreton and colleagues were the first, who administered alemtuzumab monotherapy in a phase II study cohort of 91 heavily pretreated (44 fludarabine refractory) CLL patients not according to a fixed treatment schedule, but until the maximal possible response including MRD negativity was reached. ${ }^{34}$ Alemtuzumab was applied at $30 \mathrm{mg}$ iv tiw for a median duration of 9 weeks. The length of therapy was directed by 4-weekly MRD levels in bone marrow as analyzed by four-color-flow cytometry. Grade III/IV neutropenia and thrombocytopenia were common hematological toxicities and observed in $48 \%$ and $46 \%$, respectively. Infectious grade III to IV complications occurred in 33 cases (36.3\%), the most frequent were pulmonary infections and CMV reactivations that all had been manageable. The ORR was 55\% (36\% CR and $19 \%$ PR). Eighteen of 49 complete responders (36.7\%) achieved MRD negativity in bone marrow. Treatment-free and OS was significantly prolonged in MRD-negative patients compared to MRD-positive CR, PR or responders or nonresponders: in recently updated long-term data the median OS for all 18 MRD-negative responders had not been reached after a median follow up of 77 months (range 5-123 months). ${ }^{65}$ At 72 months $66 \%$ of these patients were alive. The median OS for 8 fludarabine-refractory patients achieving undetectable MRD was determined at 87 months. At the time of update, 72\% (13/18) of MRD-depleted CRs had not required any further therapy. In contrast, MRD-positive responders survived for a median of 56 and 42 months (CR and PR, respectively) compared to 14 months in non-responders.

This study clearly demonstrated the capability of alemtuzumab to eradicate MRD and the successful translation of MRD-negative remissions into a prolonged treatment-free and OS in CLL. Although the inclusion of fewer patients with bulky lymphadenopathy might explain the relatively high number of CRs in this usually difficult to treat trial population, the MRD status differentiated PFS and OS better than the clinically determined quality of response $(\mathrm{CR} / \mathrm{PR} /$ NR). Hence, the rate of MRD-negative remissions comprises an important treatment endpoint in any clinical trial implementing alemtuzumab-based treatment strategies.

\section{Efficacy and safety studies on alemtuzumab regimens with first-line potential} Alemtuzumab is one of the most active
single agents in the CLL front-line setting In CLL front-line treatment, encouraging ORR achieved by alemtuzumab were first reported by Osterborg and colleagues in $1996 .{ }^{58}$ In their pilot study 9 patients received first-line alemtuzumab, $30 \mathrm{mg}$ tiw iv or sc for up to 18 weeks. 8 of them responded, 3 patients achieved a CR. Except one CMVrelated pneumonia, no major toxicity was observed. In an extended phase II study, Lundin and colleagues demonstrated in 41 patients that first-line alemtuzumab given sc for up to 18 weeks (30 mg tiw) achieved an ORR of $87 \%$ including $19 \%$ CR..$^{53}$ The complete reduction of lymphadenopathy $(29 \%)$ was significantly less frequent than complete clearance of CLL cells from blood (95\%) and bone marrow (45\%). The majority of patients reached best response in bone marrow after full completion of 18 weeks' treatment. Twenty-one percent of patients developed transient grade IV neutropenia, but infectious complications were rare. No bacterial infections, only 4 asymptomatic CMV reactivations and 1 pneumocystis pneumonia in a patient, who did not receive proper prophylaxis, were reported. In an updated long-term analysis, the median time to treatment failure was determined at 28 months (range 4 to $102+$ months). ${ }^{66}$

The first and only randomized phase III study (CAM307) addressing alemtuzumab first-line treatment compared alemtuzumab (30 mg iv tiw for 12 weeks) with chlorambucil (40 $\mathrm{mg} / \mathrm{m}^{2}$ orally once every 28 days for up to 12 cycles) for front-line therapy. ${ }^{59}$ As expected, the number and quality of responses were significantly higher in the alemtuzumab group (ORR 83\%, CR 24\%) than in chlorambucil-treated patients (ORR 55\%, CR 2\%, $P<0.0001$ ). In terms of response, high-risk patients with deletions on chromosome 11 or 17 , as detected by FISH, benefited from alemtuzumab; however a significant improvement in PFS could be demonstrated only patients with $13 \mathrm{q}$ deletions. Also elderly patients ( $\geq 65$ years) responded significantly better to alemtuzumab than to chlorambucil, though again without a corresponding change in PFS. MRD assessment was performed in complete 
responders by four-color flow cytometry: Strikingly, 30\% (11/36) of patients in CR after alemtuzumab achieved an MRD-negative response by four-color flow versus $0 \%$ in the chlorambucil arm. Both, median PFS and time to alternative treatment (TTT) were significantly prolonged in the alemtuzumab versus chlorambucil group (median PFS 14.6 versus 11.7 months, median TTT 23.3 versus 14.7 months, respectively). MRD-negative responders to alemtuzumab had a significantly longer PFS than MRD-positive. No difference in OS was seen after a fairly short median follow-up of 24.6 months, with $84 \%$ of patients alive in each arm. Significant neutropenias ( $46 \%$ versus $28 \% ; P=0.002)$ and mostly asymptomatic CMV infections (69\% versus $8 \%$ ) occurred more frequently in the alemtuzumab than in the chlorambucil arm; however, the overall incidence of infections (excluding CMV) did not differ. Not surprisingly, the results of this trial indicated the superiority of alemtuzumab compared to chlorambucil as first-line treatment in CLL with reasonable response rates and safety profile. Thrombopenias and infections were less frequent compared to studies in relapsed/refractory CLL, which corroborates an elevated risk of adverse events in advanced CLL patients with decreased bone marrow reserves and immunosurveillance. The efficacy of alemtuzumab at least equals, if not surpasses, the one of purine analogues in the CLL front-line treatment setting (Table 1). Therefore, the Food and Drug Administration
(FDA) and the European Medicines Agency (EMEA) have recently extended their approval of alemtuzumab for untreated CLL (FDA). The EMEA additionally specified approval for those untreated patients not eligible for fludarabine-based combination treatment.

\section{Alemtuzumab based combination therapy: The FluCam regimen and more}

The in vitro observation of complementary or synergistic anti-leukemic drug activity, encouraged combining alemtuzumab with chemotherapy or other monoclonal antibodies (see "Pharmacocharacteristics of alemtuzumab"). Only a few studies investigating the efficacy of alemtuzumab combinations, many in relapsed CLL, have been published to date and will be discussed here; however, further results of several phase II and randomized trials running in the first-line setting are pending (published data are summarized in Table 2).

In the so far largest phase II study on immunochemotherapy with alemtuzumab, 36 relapsed/refractory and heavily pretreated CLL patients (25\% fludarabine refractory, range of treatments 1-8) received up to six 4-weekly cycles of "FluCam", which consisted of fludarabine $30 \mathrm{mg} / \mathrm{m}^{2}$ iv (day 1-3) plus alemtuzumab $30 \mathrm{mg}$ iv (day 1-3). The age range of treated patients was 38 to 80 years (median 61.5 ). The overall response rate was very promising with $83 \%$ including $30 \% \mathrm{CR}$ and $53 \% \mathrm{PR}$. According to the

Table 2 Alemtuzumab-based combinations in current clinical trials (previously untreated chronic lymphocytic leukemia)

\begin{tabular}{|c|c|c|c|c|c|c|c|}
\hline Drug & Trial identifier & Author & Trial Phase & No. of pts & Maximum dose & ORR (\%) & CR (\%) \\
\hline \multirow[t]{2}{*}{$\begin{array}{l}\text { FluCam (high risk) } \\
\text { or } \\
\text { FC (low risk) }\end{array}$} & $\begin{array}{l}\text { GIMEMA } \\
\text { Multicenter } \\
\text { LLC0405 }\end{array}$ & Mauro et $\mathrm{a}^{68}$ & II & 74 & $\begin{array}{l}\text { Fludarabine } 30 \mathrm{mg} / \mathrm{m}^{2} \text { iv }+ \\
\text { alemtuzumab } 30 \mathrm{mg} \text { iv, } \\
\mathrm{dl}-3, \text { q28d,4 cycles (high risk) } \\
\text { or }\end{array}$ & 71 & 30 \\
\hline & & & & & $\begin{array}{l}\text { Fludarabine } 30 \mathrm{mg} / \mathrm{m}^{2} \text { iv }+ \\
\text { cyclophosphamide } 250 \mathrm{mg} / \mathrm{m}^{2} \text {, } \\
\mathrm{dl}-3, \text { q28d, } 6 \text { cycles (low risk) }\end{array}$ & 95 & 57 \\
\hline $\begin{array}{l}\text { Cam-Pred } \\
\text { (high-risk only) }\end{array}$ & NCRI CLL206 & Pettitt et $\mathrm{al}^{73}$ & II & 17 & $\begin{array}{l}\text { Alemtuzumab } 30 \mathrm{mg} \text { tiw up to } \\
16 \text { weeks + methylprednisolone } \\
1.0 \mathrm{~g} / \mathrm{m}^{2} \mathrm{dI}-5 \text { weeks } \mathrm{I}, 5,9,13\end{array}$ & $\mathrm{nk}$ & 37 \\
\hline $\begin{array}{l}\text { Alemtuzumab }+ \\
\text { rituximab at early } \\
\text { stage (high-risk only) }\end{array}$ & nk & Zent et $\mathrm{a}^{78}$ & ॥ & 30 & $\begin{array}{l}\text { Alemtuzumab } 30 \mathrm{mg} \text { tiw + } \\
\text { rituximab } 375 \mathrm{mg} / \mathrm{m}^{2} \text { qwk, } \\
4 \text { weeks }\end{array}$ & 90 & 37 \\
\hline $\begin{array}{l}\text { Alemtuzumab + } \\
\text { rituximab }\end{array}$ & nk & Frankfurt et al ${ }^{77}$ & ॥ & 21 & $\begin{array}{l}\text { Alemtuzumab } 30 \mathrm{mg} \text { tiw, } 17 \\
\text { weeks + rituximab } 375 \mathrm{mg} / \mathrm{m}^{2} \\
\text { every other week, } 8 \text { times }\end{array}$ & 90 & 75 \\
\hline CFAR (high risk only) & nk & Wierda et $\mathrm{al}^{76}$ & II & 60 & $\begin{array}{l}\text { Fludarabine } 20 \mathrm{mg} / \mathrm{m}^{2} \mathrm{~d} 3-5+ \\
\text { cyclophosphamide } 200 \mathrm{mg} / \mathrm{m}^{2} \\
\mathrm{~d} 3-5+\text { rituximab } 375-500 \\
\mathrm{mg} / \mathrm{m}^{2} \mathrm{~d} 2+\text { alemtuzumab } \\
30 \mathrm{mg} \text { tiw, q28d,4 cycles }\end{array}$ & 94 & 69 \\
\hline
\end{tabular}

Abbreviations: d, day; nk, unknown; q28d, administered every 28 days/4-weekly; qwk, administered every week; tiw, administered 3 times per week. 
investigators, responding patients with lymphadenopathy benefited particularly from synergistic activity of alemtuzumab and fludarabine. The median OS was 35.6 months for all patients and had not been reached for responders at the time of publication. ${ }^{67}$ The median TTP in responders was reported at 21.9 months compared to 12.97 months for all patients. Despite the dual treatment on day 1 to 3 , acute infusion-related side effects were mild (grade I and II) and disappeared with repeated dosing. Grade III and IV myelosuppression were the most frequent adverse events, mostly neutropenias and thrombocytopenias in $26 \%$ and $30 \%$ of patients, respectively. Grade IV infections with fatal outcome (= final grade V) were seen in 3 patients, of whom 2 were refractory to both, prior therapy and FluCam (2 fungal pneumonias, 1 E. coli sepsis). Surprisingly, only 3 subclinical CMV reactivations occurred, although the majority of patients presented with a CMV-antiglobulin positive status prior to treatment.

Overall, the trial demonstrated the clinical feasibility, safety and efficacy of two potentially immunosuppressive drugs combined in one regimen, even in advanced, elderly or heavily pretreated and therefore immunocompromised patients. Infections were less frequent than expected from other studies with single agent alemtuzumab in advanced CLL. However, the relatively low cumulative dose of alemtuzumab in a 4- to 6-cycle FluCam regimen needs to be considered. Unfortunately, the study was not designed to assess treatment efficacy and long-term outcome in biological risk groups and according to MRD course. First interim data of a current phase III registration trial (CAM314), comparing $\mathrm{F}$ versus FluCam in relapsed CLL, are currently being prepared for publication.

First-line FluCam is presumably more effective in high-risk patients than alemtuzumab or chemotherapy alone. Based on this hypothesis, an Italian multicenter trial (GIMEMA Multicenter LLC0405 Study) is currently investigating whether the promising activity of FluCam can be reiterated in untreated young CLL patients with biological high-risk features. ${ }^{68}$ CLL patients $\leq 60$ years of age with advanced or progressive disease are stratified as either high-risk or low-risk and receive 4 courses of FluCam or 6 cycles of FC chemotherapy, respectively. High risk patients are separated from low risk by the presence of either $17 \mathrm{p}$ deletion ( $\geq 20 \%$ ), or $11 \mathrm{q}$ deletion plus $\geq 1$, or an unmutated IGHV status plus $\geq 2$ adverse prognostic factors (ZAP70+ $\geq 10 \%, \mathrm{CD} 38+\geq 7 \%, 6 \mathrm{q}$ deletion or trisomy 12 , unmuated IGHV). In case of detectable residual disease after FluCam by CT scan, flow cytometry and/or PCR and availability of a sibling donor, high risk patients continue treatment receiving a reduced intensity allogeneic stem cell transplant. Alternatively, an autologous PBSC transplant or a 12-week alemtuzumab consolidation can replace the allogeneic transplant, in case no donor is available or stem cell harvest is insufficient. In a first analysis, presented at the annual meeting of the American Hematological Society ASH $2008,{ }^{68} 74$ patients had been recruited, 45 treated, including 24 high-risk patients. Seventy-one percent of high risk patients had responded, with 30\% CR and 17\% MRD negative responses. In the low risk group the ORR was $95 \%$ with 57\% CR and 19\% MRD negativity. Patients refractory to FluCam were reported as either $17 \mathrm{p}$-deleted or cases with bulky lymphadenopathy. As the most common toxicity, grade III-IV neutropenia was observed after both, FC and FluCam. CMV reactivation was the most frequent adverse event after FluCam. At the time of the report, 9 patients had been transplanted (3 allogeneic, 6 autologous).

The study demonstrates an appealing concept of how to interconnect biological risk to different levels of front-line treatment intensity. The choice of FC as the selected therapeutic regimen for low-risk patients might be questionable; obviously FCR would have been the recommended option nowadays, especially in this young and biologically "fit" patient population. However, first results suggest that in highrisk patients, especially with $17 \mathrm{p}$ deletion, front-line FluCam might be as limited in activity as FCR for the number of achieved CRs. One reason could be the missing impact of the alkylator cyclophosphamide to decrease lymphadenopathy. However, data on long-term outcome of high-risk patients treated with front-line FluCam compared to FCR are needed to draw further conclusions.

Unfortunately, the addition of the alkylator cyclophosphamide to the FluCam regimen, resembling combined fludarabine, cyclophosphamide plus alemtuzumab (FCCam or FCC) has recently been found to harbor an extended risk of toxicity: in a study by the GCLLSG administering FCCam in previously treated CLL (CLL2L trial), an increased number of sepsis or septic shock was observed. ${ }^{69,70}$ Other phase III trials investigating the more aggressive triple combination FCCam in first-line CLL are being performed by Dutch (HOVON 68, FC versus FCCam in high-risk patients) and French study groups (CLL2007FMP, FCR versus FCCam). The latter has recently been prematurely terminated due to severe toxicity in the FCCam arm including severe infections with fatal outcome. ${ }^{71}$ Therefore, further intensification of the FluCam regimen with cyclophosphamide cannot currently be recommended within or outside clinical trials. 


\section{Alemtuzumab plus high-dose corticosteroids}

Based on the ability of steroids to induce p53-independent apoptosis and in order to amplify treatment activity in lymph nodes, investigators have combined alemtuzumab plus high-dose corticosteroids for CLL treatment. ${ }^{72}$ First data of the British NCRI CLL206 phase II trial were presented by Pettitt and colleagues at the Annual Meeting of the European Hematology Association 2009. ${ }^{73}$ The trial included pre- and non-treated patients exhibiting at least $20 \%$ of CLL cells as being $17 \mathrm{p}$-deleted. Briefly, alemtuzumab was administered $30 \mathrm{mg}$ tiw for up to 16 weeks (4 weeks iv, followed by sc application) plus methylprednisolone $1.0 \mathrm{~g} / \mathrm{m}^{2}$ day $1-5$ in week 1, 5, 9 and 13 under a broad antimicrobial prophylaxis. In 39 treated patients ( 22 with prior therapy, 17 untreated) the $\mathrm{CR} / \mathrm{CRi}^{35}$ rate was reported as overall $24 \%$ and $37 \%$ in previously untreated patients. Additionally, 3 patients achieved a confirmed MRD-negative CR/CRi. ${ }^{35}$ However, toxicity of this apparently very effective regimen was fairly high. While the rate of CMV infections was not increased, $41 \%$ of grade III to IV non-CMV infections and $38 \%$ of glucocorticoid-related toxicity occurred. Four patients died of infections. A full report with upated information on toxicity, PFS and OS has to be awaited to evaluate whether this regimen is clinically feasible. A German phase-II trial exploring the efficacy of alemtuzumab plus dexamethasone in patients with purineanalog refractory disease and/or presence of $17 \mathrm{p}$-deletion is currently ongoing (CLL2O).

\section{FCR plus alemtuzumab - CFAR}

One of the first studies investigating a combination regimen containing alemtuzumab in treatment-naïve patients was performed at the University of Texas M. D. Anderson Cancer Center. The trial rationale was based on the synergistic pro-apoptotic effect of both rituximab and alemtuzumab on CLL cells as confirmed in vitro. ${ }^{46}$ Simultaneous treatment with fludarabine, cyclophosphamide, rituximab plus alemtuzumab (CFAR) had first been tested in a phase II study in 79 treatment-refractory patients, in which an ORR of $65 \%$ and a CR rate of $24 \%$ were observed. ${ }^{74}$ All 18 patients in $\mathrm{CR}$ presented with bone marrow free of residual disease by two-color flow analysis. Forty-four percent of patients with 17p-deletion responded to CFAR. Myelosuppression was the most frequent toxicity. ${ }^{75}$ The same regimen (fludarabine $20 \mathrm{mg} / \mathrm{m}^{2}$ day $3-5$, cyclophosphamide $200 \mathrm{mg} / \mathrm{m}^{2}$ day $3-5$; rituximab $375-500 \mathrm{mg} / \mathrm{m}^{2}$ day 2 ; and alemtuzumab $30 \mathrm{mg}$ days 1, 3 and 5, 4-weekly) was subsequently tested in untreated high-risk patients, determined as either FISH positive for $17 \mathrm{p}$-deletion or with a beta2-microglobulin level higher than twice the upper limit of normal. The data of 59 evaluable patients ( $23 \%$ with $17 \mathrm{p}$ deletion) were recently updated (ASH $2009^{76}$ ): the ORR was determined at $92 \%$ with $70 \% \mathrm{CR}$. Of 14 patients with $17 \mathrm{p}$-deletion, $78 \%$ responded and $57 \%$ achieved a CR. In a retrospective comparative analysis of high-risk patients treated with CFAR and matched historical cases treated with FCR, CFAR was associated with higher rates of myelosuppression, treatment discontinuation and CMV reactivations. There was no difference in other infections. However, treatment with CFAR achieved more frequently MRD negativity in bone marrow as assessed by two-color flow cytometry. With a short median follow-up of 24 months, no difference in time to progression or OS, comparing CFAR and FCR in the retrospective historical analysis, could be revealed.

Overall, the data suggest that CFAR is a highly active and surprisingly tolerable first-line regimen in high-risk CLL patients. It demonstrated the highest rate so far of achievable CRs in patients with $17 \mathrm{p}$ deletions; however, a corresponding long-term benefit in these patients is yet to become evident Longer follow-up data on all 60 enrolled patients from the M.D. Anderson Cancer Center trial might help to determine the potential of CFAR within the CLL front-line algorithm. Given the negative experience with FCCam discussed above, major concerns to be clarified are whether long-term efficacy translates into a survival advantage with an acceptable amount of early and late toxicity (compared to the new standard FCR and to FluCam), and which salvage options can yet be offered to patients after CFAR failure.

\section{Alemtuzumab plus rituximab}

Two studies have investigated the potential synergism of monoclonal antibodies rituximab and alemtuzumab without any chemotherapeutic "backbone" in untreated CLL patients. A phase II study applying combined alemtuzumab and rituximab in untreated CLL patients requiring therapy is currently being performed by Frankfurt and colleagues, with first data in a small number of patients available. ${ }^{77}$ Zent and colleagues implemented a risk-stratified study approach to treat early stage CLL patients with rituximab plus alemtuzumab. A tailored alemtuzumab regimen of $30 \mathrm{mg}$ tiw for 4 weeks plus rituximab $375 \mathrm{mg} / \mathrm{m}^{2}$ once weekly was given in 30 early stage (Rai 0 -II) patients, who did not require treatment according to current guidelines, but had at least one marker positive for high-risk disease (17p- or 11q-deletion, or a combination of unmutated IGHV and CD38-/ZAP70positivity). ${ }^{78}$ Twenty-seven of 30 patients responded, and 
11 patients achieved a CR (37\%). Six patients were MRD negative according to three-color flow cytometry of peripheral blood. Toxicity was acceptable, with mainly cytopenias (neutropenias and monocytopenias), $3 \mathrm{CMV}$ reactivations and 1 skin infection, all of them reversible. The median duration of response in the 27 responders was 14.4 months, and the median TTP was reported at 12.5 months for all patients. Interestingly, the investigators repeated FISH analysis in patients with progressive disease and could not find evidence of clonal selection or evolution after treatment. In comparison with biologically matched historical controls, a significantly longer time from diagnosis to initial treatment was detected in patients treated with alemtuzumab plus rituximab (4.4 years) compared to patients who had been observed (1.9 years, "watch and wait"). The trial rationale addressed an unsolved question, namely whether single-agent monoclonal antibodies are able to affect the disease course and long-term outcome, if used in early stage CLL. Despite the presumably lower disease load in RAI stage 0-II patients, alemtuzumab was acceptably tolerated. The results are promising, but need to be further studied in a larger, eventually randomized, trial.

Moreover, the combination of the monoclonal antibodies alemtuzumab and rituximab might be useful as a front-line regimen in patients, who require treatment but are not suitable for aggressive combinations containing chemotherapy (ie, elderly but biologically fit, patients with intolerance of fludarabine, for example).

\section{Alemtuzumab consolidation following front-line induction therapy}

The therapeutic goal of consolidation as a treatment strategy is to achieve the best quality and duration of remissions on a morphological and molecular level. Ideally, this can be accomplished by shifting the response to induction treatment from an MRD-positive CR/PR or nodular PR to a MRDnegative CR. Based on the concept of "in vivo purging" of residual disease, ${ }^{79}$ several investigators and study groups have tested various schedules of alemtuzumab consolidation.

\section{Consolidation after chemotherapy}

An M.D. Anderson study, one of the first using alemtuzumab consolidation, treated overall 58 patients in at least PR after remission induction by various numbers and types of treatment. ${ }^{80}$ Patients received either $10 \mathrm{mg}$ or $30 \mathrm{mg}$ alemtuzumab tiw for 4 weeks. After consolidation, approximately half of the patients in previous PR could improve their response status (ORR 53\%). The major reason for response failure was the presence of residual lymphadenopathy. Eighty-six percent of 29 evaluable patients achieved MRD negativity by two-color flow cytometry, and $11 / 29$ or $38 \%$ a molecular remission by PCR in bone marrow after alemtuzumab consolidation. At a median follow up of 18 months TTP was improved in the PCR-negative group compared to all other patients (median not reached versus 15 months). Grade III and IV hematological toxicity was more common in the $30 \mathrm{mg}$ than in the $10 \mathrm{mg}$ group (71\% versus $17 \%$ ). Infections occurred in $37 \%$ of patients. However, all of these were manageable, except 1 fatality due to fulminant CMV hepatitis. Interestingly, 3 patients developed an EpsteinBarr virus-positive large cell lymphoma, which also resolved in all cases without any further treatment. ${ }^{80,81}$ An equivalent trial administering alemtuzumab $30 \mathrm{mg}$ tiw sc after remission induction for up to 8 weeks is ongoing. ${ }^{81}$

Montillo and colleagues treated 34 patients in first remission after fludarabine-based induction (median 6 cycles fludarabine or FC), with alemtuzumab consolidation $10 \mathrm{mg}$ sc tiw for 6 weeks. ${ }^{55}$ The median interval between last dose of induction and start of consolidation was 16 weeks (range 12 to 76 weeks). MRD assessment was performed by consensus primer IGHV PCR. The CR rate improved significantly from $35 \%$ after induction to $79.5 \%$ after alemtuzumab consolidation. Whereas none of the patients had been MRD negative in bone marrow after fludarabine induction, $56 \%$ were in molecular remission after alemtuzumab. Side effects were notably rare with no major hematological toxicity, only asymptomatic CMV reactivations occurred. Harvest of peripheral blood stem cells was successfully performed in 24 of 26 patients and 18 patients underwent subsequent autologous stem cell transplantation. At a median follow up of 28 months after alemtuzumab 17 of the 18 transplanted patients were still in CR. 9 of 16 patients who did not undergo autologous transplantation were progression free at a median follow up of 17 months.

The GCLLSG conducted the only available randomized phase III trial addressing alemtuzumab consolidation in first remission after fludarabine-based treatment: ${ }^{82,83}$ CLL patients in CR or PR after fludarabine or fludarabine/cyclophosphamide chemotherapy were randomized to either receive alemtuzumab (30 mg iv tiw, 12 weeks) or observation with no further treatment. After inclusion of 21 patients the trial had to be stopped prematurely due to grade III and IV infections in 7 of 11 patients under alemtuzumab, all of which could be successfully treated. After consolidation 5 of 6 patients (83\%) achieved a molecular remission in peripheral blood confirmed by allele-specific primer IGHV PCR. Molecular follow up revealed sustained MRD reduction below $0.01 \%$ for approximately 1 year. Updated results with a median follow up of 48 months showed a significantly improved PFS in the alemtuzumab arm compared to 
the observation cohort (10 patients, median not reached versus 20.6 months, $P=0.0035){ }^{82}$

Based on this experience the GCLLSG recently launched a phase I/II dose escalation trial to determine the maximum tolerated dose (MTD) and dose-limiting toxicities (DLT) of iv or sc alemtuzumab for consolidation treatment. ${ }^{84}$ Additional safety measures have been taken in this study: patients in a later stage of disease, in CR or PR following second-line purine-analog based induction, have been included. Furthermore, inclusion required a minimum interval of 90 days after last induction dose in order to start consolidation. Alemtuzumab dose escalation was started at a dose level of $10 \mathrm{mg}$ iv/sc weekly and increased in $10 \mathrm{mg}$ intervals to subsequent dose levels, each of them including minimally 3 patients. First results suggest that due to 2 DLT, the MTD of alemtuzumab consolidation was defined at $10 \mathrm{mg}$ iv in 10 patients, a result in accordance with the data by Montillo and colleagues also favoring a low dose of alemtuzumab in the consolidation/maintenance setting.

\section{Consolidation after immunochemotherapy}

Unexpected high toxicity has been observed in the Cancer and Leukemia Group B (CALGB) initiated phase II study administering alemtuzumab for remission consolidation in CLL patients previously treated with up to 6 cycles of fludarabine plus rituximab (FR) as a front-line regimen. After an interval of 4 months following the last dose of fludarabine, patients with stable disease or any remission received alemtuzumab consolidation with $30 \mathrm{mg}$ sc tiw for 6 weeks. Safety data on 51 patients were first reported in $2007::^{85}$ despite standard Pneumocystis (PCP) and varicella zoster virus prophylaxis and careful monitoring for CMV reactivation, 9 of 34 patients in PR after FR induction (26\%) experienced unacceptable toxicity. Eight grade III toxicities (4 opportunistic infections, $3 \mathrm{CMV}$ reactivations, 1 hemorrhagic cystitis), and 1 fatal EBV lymphoproliferative disorder were observed. Of 17 patients in CR after FR induction, 8 (47\%) underwent grade III-V toxicity: 3 grade III infections (2 CMV, 1 Cryptococcus) and 5 fatal (grade V) infections (viral meningitis, Listeria meningitis, Legionella pneumonia, CMV and Pneumocystis pneumonia) were reported. Infections occurred during therapy or with a latency of up to 16 months after consolidation. It was assumed, that toxicity of alemtuzumab was increased in complete responders due to less antigen availability on malignant cells after FR induction. The authors concluded that alemtuzumab consolidation is not safe in patients in CR after chemoimmunotherapy. The study has been amended after this experience, excluding patients in $\mathrm{CR}$ after FR induction.

Another experience in FR-treated patients was recently reported by Hainsworth et $\mathrm{al}^{86} 34$ patients had been treated after 4 cycles of FR with up to 4 weeks of $30 \mathrm{mg}$ alemtuzumab iv tiw. Alemtuzumab was poorly tolerated with frequent infusion related side effects, particularly if given less than 5 weeks after the last induction cycle. CMV infections were observed in 6 patients and 2 treatment-related fatalities were reported (1 CMV exacerbation, 1 unclear wasting syndrome). Also an unsatisfying response was observed in this trial: only 5 patients went into an improved remission status (21\%). A high frequency of residual adenopathy after induction, the inclusion of a fair number of SLL patients and the frequent abortion of alemtuzumab treatment (in 51\%) were discussed by the authors as possible causes to explain the low response rate. The median PFS for all patients calculated from start of induction was reported at 42 months.

Overall, clinical investigation of the consolidation concept in CLL confirmed a reproducible correlation between MRD negativity achieved by alemtuzumab therapy and prolonged PFS. Unfortunately, data on OS are not available and the only randomized trial stopped prematurely with a small study population. However, due to the observed toxicity in clinical trials, alemtuzumab consolidation after frontline induction cannot be recommended as a feasible approach for clinical practice. It is obsolete to administer alemtuzumab for consolidation after full induction with $\mathrm{F}(\mathrm{C}) \mathrm{R}$-related immunochemotherapy. In the above-mentioned trials, recurrent and cumulative immunosuppression by the combined depletion of $\mathrm{B}$ cells and $\mathrm{T}$ cells over a relatively long period of time ( $>6$ months) might have contributed to the observed severe and life threatening infections. Also, inter-patient variability in biological risk, disease load and dissemination (adenopathy versus bone marrow), and in the level of immune reconstitution since last dose after induction, for example, might have effectuated adverse tolerability. Ongoing and future trials investigating alemtuzumab or alternative consolidation therapies should study carefully the maximum tolerable dosing, way of application, timing and duration of the applied consolidating regimen. Further, a comprehensive clinical and molecular characterization of patient subsets who do or do not benefit from consolidation should be delivered.

\section{Role in therapy and conclusions}

In conclusion, alemtuzumab is a powerful and powerful drug in the arsenal of CLL therapeutics, approved for therapy of 
untreated and relapsed CLL. The antibody "purges" CLL cells in vivo very efficiently from peripheral blood and bone marrow and has been used successfully for MRD eradicating treatment strategies. Due to the concomitant depletion of B- and T-lymphocytes, infectious events have been common under alemtuzumab and require careful monitoring, prophylaxis and a high standard of care in experienced and specialized treatment centers. In general, treatment using this antibody should not be employed too late in the disease course, since the additional disease- or age/comorbidity-related impairment of the immune system might increase the risk of infectious complications.

Alemtuzumab is one of the most effective single agents in CLL and a definite treatment option in relapsed/refractory CLL with high-risk features and inferior prognosis. Although the CAM307 trial has shown superiority of alemtuzumab versus chlorambucil in untreated patients, a putative standard role of alemtuzumab in first-line treatment needs to be further elucidated, particularly in comparison to the new frontline standard FCR. So far, only patients who are not eligible for FC or FCR immunochemotherapy, ie, elderly, comorbid but yet physically fit patients (ie, with decreased renal function) can be recommended as potentially benefiting from first-line alemtuzumab monotherapy. According to current guidelines, patients with CLL-related severe pancytopenia or autoimmune hemolysis resistant to conventional treatments may also be considered for front-line alemtuzumab. ${ }^{49}$

One flaw of the antibody is the unsatisfying activity on lymphadenopathy, which explains the limited rate of complete responders after alemtuzumab single-agent therapy alemtuzumab. Therefore, major study groups are currently investigating combination regimens in both previously treated and untreated patients. Most promising are combinations with steroids and purine analogous (chemotherapy) or rituximab (chemoimmunotherapy); however, at present alemtuzumab combinations should be applied only within clinical trials, especially in the front-line setting.

High-risk CLL patients with 17p/TP53 abnormalities have the worst prognosis, even after FCR induction. They seem to benefit particularly from the p53 independent activity of alemtuzumab treatment. More studies with careful biological stratification and adequate clinical and biological long-term follow-up are required to answer whether single or combined treatment with alemtuzumab might be the approach of choice for first-line therapy in these patients. In addition, alternative therapies including allogeneic stem cell transplant and potent new agents (ie, immunomodulatory drugs such as lenalidomide, the cyclin-dependent kinase inhibitor flavopiridol, new CD20 antibodies ofatumumab GA101) need to be investigated in comprehensive clinical trials applying innovative treatment options tailored to individual molecular profiles of disease risk and prognosis.

\section{Disclosures}

CDS declares no conflicts. CMW has received research funding from Bayer Schering.

\section{References}

1. Surveillance Epidemiology and End Results (Seer) cancer statistics review 1975-2006. Bethesda, MA/USA: National Cancer Institute. [updated April 2009, cited Oct 2009]. http://seer.cancer.gov/csr/ 1975_2006/.

2. Dighiero G, Binet JL. When and how to treat chronic lymphocytic leukemia. N Engl J Med. 2000;343(24):1799-1801.

3. Rozman C, Montserrat E. Chronic lymphocytic leukemia. $N$ Engl J Med. 1995;333(16):1052-1057.

4. Dohner H, Stilgenbauer S, Benner A, et al. Genomic aberrations and survival in chronic lymphocytic leukemia. $N$ Engl J Med. 2000;343(26):1910-1916.

5. Dohner H, Stilgenbauer S, Dohner K, Bentz M, Lichter P. Chromosome aberrations in B-cell chronic lymphocytic leukemia: reassessment based on molecular cytogenetic analysis. J Mol Med. 1999;77(2): 266-281.

6. Cordone I, Masi S, Mauro FR, et al. p53 expression in B-cell chronic lymphocytic leukemia: a marker of disease progression and poor prognosis. Blood. 1998;91(11):4342-4349.

7. Dohner H, Fischer K, Bentz M, et al. p53 gene deletion predicts for poor survival and non-response to therapy with purine analogs in chronic B-cell leukemias. Blood. 1995;85(6):1580-1589.

8. Byrd JC, Gribben JG, Peterson BL, et al. Select high-risk genetic features predict earlier progression following chemoimmunotherapy with fludarabine and rituximab in chronic lymphocytic leukemia: justification for risk-adapted therapy. J Clin Oncol. 2006;24(3):437-443.

9. Catovsky D, Richards S, Matutes E, et al. Assessment of fludarabine plus cyclophosphamide for patients with chronic lymphocytic leukaemia (the LRF CLL4 Trial): a randomised controlled trial. Lancet. 2007;370(9583):230-239.

10. Stilgenbauer S, Krober A, Busch R, et al. 17p Deletion predicts for inferior overall survival after fludarabine-based first line therapy in chronic lymphocytic leukemia: first analysis of genetics in the CLL4 trial of the GCLLSG. ASH Annual Meeting Abstracts. 2005;106(11):715.

11. Keating MJ, O’Brien S, Kontoyiannis D, et al. Results of first salvage therapy for patients refractory to a fludarabine regimen in chronic lymphocytic leukemia. Leuk Lymphoma. 2002;43(9):1755-1762.

12. Austen B, Skowronska A, Baker C, et al. Mutation status of the residual ATM allele is an important determinant of the cellular response to chemotherapy and survival in patients with chronic lymphocytic leukemia containing an 11q deletion. J Clin Oncol. 2007;25(34): 5448-5457.

13. Damle RN, Wasil T, Fais F, et al. Ig V gene mutation status and CD38 expression as novel prognostic indicators in chronic lymphocytic leukemia. Blood. 1999;94(6):1840-1847.

14. Hamblin TJ, Davis Z, Gardiner A, Oscier DG, Stevenson FK. Unmutated $\mathrm{Ig} \mathrm{V}(\mathrm{H})$ genes are associated with a more aggressive form of chronic lymphocytic leukemia. Blood. 1999;94(6):1848-1854.

15. Crespo M, Bosch F, Villamor N, et al. ZAP-70 expression as a surrogate for immunoglobulin-variable-region mutations in chronic lymphocytic leukemia. N Engl J Med. 2003;348(18):1764-1775.

16. Dighiero G, Maloum K, Desablens B, et al. Chlorambucil in indolent chronic lymphocytic leukemia. French Cooperative Group on Chronic Lymphocytic Leukemia. N Engl J Med. 1998;338(21):1506-1514. 
17. Hallek M, Fingerle-Rowson G, Fink A-M, et al. First-Line treatment with tludarabine (F), cyclophosphamide (C), and rituximab (R) (FCR) improves overall survival (OS) in previously untreated patients (pts) with advanced chronic lymphocytic leukemia (CLL): Results of a randomized phase III trial on behalf of an international group of investigators and the German CLL Study Group. Blood. 2009;114:535.

18. Keating MJ, O'Brien S, Albitar M, et al. Early results of a chemoimmunotherapy regimen of fludarabine, cyclophosphamide, and rituximab as initial therapy for chronic lymphocytic leukemia. J Clin Oncol. 2005;23(18):4079-4088.

19. Tam CS, O'Brien S, Wierda W, et al. Long-term results of the fludarabine, cyclophosphamide, and rituximab regimen as initial therapy of chronic lymphocytic leukemia. Blood. 2008; 112(4):975-980.

20. Bosch F, Abrisqueta P, Villamor N, et al. Rituximab, fludarabine, cyclophosphamide, and mitoxantrone: a new, highly active chemoimmunotherapy regimen for chronic lymphocytic leukemia. J Clin Oncol. 2009;27(27):4578-4584.

21. Faderl S, Wierda W, O'Brien S, Ferrajoli A, Lerner S, Keating MJ. Fludarabine, cyclophosphamide, mitoxantrone plus rituximab (FCM-R) in frontline CLL $<70$ years. Leuk Res. 2010;34(3):284-288.

22. Ferrajoli A, Faderl S, O'Brien S, et al. Experience with fludarabine, cyclophosphamide, rituximab (FCR) plus GM-CSF in frontline therapy for chronic lymphocytic leukemia (CLL). Blood. 2008;112(11):3173.

23. Fischer K, Stilgenbauer S, Schweighofer CD, et al. Bendamustine in Combination with Rituximab (BR) for Patients with Relapsed Chronic Lymphocytic Leukemia (CLL): A Multicentre Phase II Trial of the German CLL Study Group (GCLLSG). Blood. 2008;112(11):330.

24. Foon KA, Boyiadzis M, Land SR, et al. Chemoimmunotherapy with low-dose fludarabine and cyclophosphamide and high dose rituximab in previously untreated patients with chronic lymphocytic leukemia. J Clin Oncol. 2009;27(4):498-503.

25. Schlette E, Admirand J, Wierda W. p53 expression by immunohistochemistry is an important determinant of survival in chronic lymphocytic leukemia patients receiving frontline chemo-immunotherapy. Leuk Lymphoma. 2009;50(10):1597-605.

26. Stilgenbauer S, Eichhorst BF, Busch R, et al. Biologic and Clinical Markers for Outcome after Fludarabine (F) or F Plus Cyclophosphamide (FC) - Comprehensive Analysis of the CLL4 Trial of the GCLLSG. Blood. 2008;112(11):2089.

27. Tsimberidou AM, Tam C, Abruzzo LV, et al. Chemoimmunotherapy may overcome the adverse prognostic significance of $11 \mathrm{q}$ deletion in previously untreated patients with chronic lymphocytic leukemia. Cancer. 2009;115(2):373-380.

28. Han T, Ohtaki K, Sadamori N, et al. Cytogenetic evidence for clonal evolution in B-cell chronic lymphocytic leukemia. Cancer Genet Cytogenet. 1986;23(4):321-328.

29. Shanafelt TD, Witzig TE, Fink SR, et al. Prospective evaluation of clonal evolution during long-term follow-up of patients with untreated early-stage chronic lymphocytic leukemia. J Clin Oncol. 2006; 24(28):4634-4641.

30. Stilgenbauer S, Sander S, Bullinger L, et al. Clonal evolution in chronic lymphocytic leukemia: acquisition of high-risk genomic aberrations associated with unmutated $\mathrm{VH}$, resistance to therapy, and short survival. Haematologica. 2007;92(9):1242-1245.

31. Bottcher S, Ritgen M, Pott C, et al. Comparative analysis of minimal residual disease detection using four-color flow cytometry, consensus IgH-PCR, and quantitative IgH PCR in CLL after allogeneic and autologous stem cell transplantation. Leukemia. 2004; 18(10):1637-1645.

32. Moreno C, Villamor N, Colomer D, et al. Clinical significance of minimal residual disease, as assessed by different techniques, after stem cell transplantation for chronic lymphocytic leukemia. Blood. 2006;107(11):4563-4569.

33. Rawstron AC, Villamor N, Ritgen M, et al. International standardized approach for flow cytometric residual disease monitoring in chronic lymphocytic leukaemia. Leukemia. 2007;21(5):956-964.
34. Moreton P, Kennedy B, Lucas G, et al. Eradication of minimal residual disease in B-cell chronic lymphocytic leukemia after alemtuzumab therapy is associated with prolonged survival. J Clin Oncol. 2005;23(13):2971-2979.

35. Hallek M, Cheson BD, Catovsky D, et al. Guidelines for the diagnosis and treatment of chronic lymphocytic leukemia: a report from the International Workshop on Chronic Lymphocytic Leukemia (IWCLL) updating the National Cancer Institute-Working Group (NCI-WG) 1996 guidelines. Blood. 2008;111(12):5446-5456. Erratum in: Blood. 2008 Dec 15;112(13):5259.

36. Zenz T, Habe S, Denzel T, Winkler D, Dohner H, Stilgenbauer S. How little is too much? p53 inactivation: from laboratory cutoff to biological basis of chemotherapy resistance. Leukemia. 2008;22(12): 2257-2258.

37. Zenz T, Krober A, Scherer K, et al. Monoallelic TP53 inactivation is associated with poor prognosis in chronic lymphocytic leukemia: results from a detailed genetic characterization with long-term follow-up. Blood. 2008;112(8):3322-3329.

38. Eichhorst BF, Busch R, Stilgenbauer S, et al. First line therapy with fludarabine compared to chlorambucil does not result in a major benefit for elderly patients with advanced chronic lymphocytic leukemia. Blood. 2009;114(16):3382-3391.

39. Hale G, Xia MQ, Tighe HP, Dyer MJ, Waldmann H. The CAMPATH-1 antigen (CDw52). Tissue Antigens. 1990;35(3):118-127.

40. Treumann A, Lifely MR, Schneider P, Ferguson MA. Primary structure of CD52. J Biol Chem. 1995;270(11):6088-6099.

41. Hale G, Bright S, Chumbley G, et al. Removal of T cells from bone marrow for transplantation: a monoclonal antilymphocyte antibody that fixes human complement. Blood. 1983;62(4):873-882.

42. Gilleece MH, Dexter TM. Effect of Campath-1H antibody on human hematopoietic progenitors in vitro. Blood. 1993;82(3):807-812.

43. Rossmann ED, Lundin J, Lenkei R, Mellstedt H, Osterborg A. Variability in B-cell antigen expression: implications for the treatment of B-cell lymphomas and leukemias with monoclonal antibodies. Hematol J. 2001;2(5):300-306.

44. Ambrose LR, Morel AS, Warrens AN. Neutrophils express CD52 and exhibit complement-mediated lysis in the presence of alemtuzumab. Blood. 2009;114(14):3052-3055.

45. Mone AP, Cheney C, Banks AL, et al. Alemtuzumab induces caspaseindependent cell death in human chronic lymphocytic leukemia cells through a lipid raft-dependent mechanism. Leukemia. 2006;20(2): 272-279.

46. Smolewski P, Szmigielska-Kaplon A, Cebula B, et al. Proapoptotic activity of alemtuzumab alone and in combination with rituximab or purine nucleoside analogues in chronic lymphocytic leukemia cells. Leuk Lymphoma. 2005;46(1):87-100.

47. Stanglmaier M, Reis S, Hallek M. Rituximab and alemtuzumab induce a nonclassic, caspase-independent apoptotic pathway in B-lymphoid cell lines and in chronic lymphocytic leukemia cells. Ann Hematol. 2004;83(10):634-645.

48. Cruz RI, Hernandez-Ilizaliturri FJ, Olejniczak S, et al. CD52 overexpression affects rituximab-associated complement-mediated cytotoxicity but not antibody-dependent cellular cytotoxicity: preclinical evidence that targeting CD52 with alemtuzumab may reverse acquired resistance to rituximab in non-Hodgkin lymphoma. Leuk Lymphoma. 2007 Dec;48(12):2424-2436.

49. Osterborg A, Foa R, Bezares RF, et al. Management guidelines for the use of alemtuzumab in chronic lymphocytic leukemia. Leukemia. 2009;23(11):1980-1988.

50. Keating MJ, Flinn I, Jain V, et al. Therapeutic role of alemtuzumab (Campath-1H) in patients who have failed fludarabine: results of a large international study. Blood. 2002;99(10):3554-3561.

51. Lundin J, Osterborg A, Brittinger G, et al. CAMPATH-1H monoclonal antibody in therapy for previously treated low-grade non-Hodgkin's lymphomas: a phase II multicenter study. European Study Group of CAMPATH-1H Treatment in Low-Grade Non-Hodgkin's Lymphoma. J Clin Oncol. 1998;16(10):3257-3263. 
52. Montillo M, Schinkoethe T, Elter T. Eradication of minimal residual disease with alemtuzumab in B-cell chronic lymphocytic leukemia (B-CLL) patients: the need for a standard method of detection and the potential impact of bone marrow clearance on disease outcome. Cancer Invest. 2005;23(6):488-496.

53. Lundin J, Kimby E, Bjorkholm M, et al. Phase II trial of subcutaneous anti-CD52 monoclonal antibody alemtuzumab (Campath-1H) as first-line treatment for patients with B-cell chronic lymphocytic leukemia (B-CLL). Blood. 2002;100(3): 768-773.

54. Montillo M, Cafro AM, Tedeschi A, et al. Safety and efficacy of subcutaneous Campath-1H for treating residual disease in patients with chronic lymphocytic leukemia responding to fludarabine. Haematologica. 2002;87(7):695-700; discussion 700.

55. Montillo M, Tedeschi A, Miqueleiz S, et al. Alemtuzumab as consolidation after a response to fludarabine is effective in purging residual disease in patients with chronic lymphocytic leukemia. J Clin Oncol. 2006;24(15):2337-2342.

56. Hale G, Rebello P, Brettman LR, et al. Blood concentrations of alemtuzumab and antiglobulin responses in patients with chronic lymphocytic leukemia following intravenous or subcutaneous routes of administration. Blood. 2004;104(4):948-955.

57. Stilgenbauer S, Zenz T, Winkler D, et al. Subcutaneous alemtuzumab in fludarabine-refractory chronic lymphocytic leukemia: clinical results and prognostic marker analyses from the CLL2H study of the German Chronic Lymphocytic Leukemia Study Group. J Clin Oncol. 2009;27(24):3994-4001.

58. Osterborg A, Fassas AS, Anagnostopoulos A, Dyer MJ, Catovsky D, Mellstedt H. Humanized CD52 monoclonal antibody Campath-1H as first-line treatment in chronic lymphocytic leukaemia. Br J Haematol. 1996;93(1):151-153.

59. Hillmen P, Skotnicki AB, Robak T, et al. Alemtuzumab compared with chlorambucil as first-line therapy for chronic lymphocytic leukemia. J Clin Oncol. 2007;25(35):5616-5623.

60. Karlsson C, Lundin J, Kimby E, et al. Phase II study of subcutaneous alemtuzumab without dose escalation in patients with advancedstage, relapsed chronic lymphocytic leukaemia. Br J Haematol. 2009;144(1):78-85.

61. Osterborg A, Dyer MJ, Bunjes D, et al. Phase II multicenter study of human CD52 antibody in previously treated chronic lymphocytic leukemia. European Study Group of CAMPATH-1H Treatment in Chronic Lymphocytic Leukemia. J Clin Oncol. 1997; 15(4):1567-1574.

62. Mould DR, Baumann A, Kuhlmann J, et al. Population pharmacokineticspharmacodynamics of alemtuzumab (Campath) in patients with chronic lymphocytic leukaemia and its link to treatment response. $\mathrm{Br} J$ Clin Pharmacol. 2007;64(3):278-291.

63. Lozanski G, Heerema NA, Flinn IW, et al. Alemtuzumab is an effective therapy for chronic lymphocytic leukemia with p53 mutations and deletions. Blood. 2004;103(9):3278-3281.

64. Osuji NC, Del Giudice I, Matutes E, Wotherspoon AC, Dearden C, Catovsky D. The efficacy of alemtuzumab for refractory chronic lymphocytic leukemia in relation to cytogenetic abnormalities of p53. Haematologica. 2005;90(10):1435-1436.

65. Sayala HA, Moreton P, Kennedy B, et al. Eradication of minimal residual disease with alemtuzumab in chronic lymphocytic leukemia is associated with prolonged survival and is an appropriate theraputic endpoint for relapsed CLL. Blood. 2007;110(11):3114.

66. Karlsson C, Norin S, Kimby E, et al. Alemtuzumab as first-line therapy for B-cell chronic lymphocytic leukemia: long-term follow-up of clinical effects, infectious complications and risk of Richter transformation. Leukemia. 2006;20(12):2204-2207.

67. Elter T, Borchmann P, Schulz H, et al. Fludarabine in combination with alemtuzumab is effective and feasible in patients with relapsed or refractory B-cell chronic lymphocytic leukemia: results of a phase II trial. J Clin Oncol. 2005;23(28):7024-7031.
68. Mauro FR, Cortelezzi A, Molica S, et al. Efficacy and safety of a firstline combined therapeutic approach for young cll patients stratified according to the biological prognostic features: first analysis of the GIMEMA multicenter LLC0405 Study. Blood. 2008;112(11):3167.

69. Elter T, James R, Stilgenbauer S, et al. Chemoimmunotherapy with fludarabine, cyclophosphamide and alemtuzumab (FC-Cam) in patients with relapsed or genetic high-risk CLL: Final analysis of the CLL2L trial of the German CLL Study Group. Blood. 2009;114:209.

70. Montillo M, Miqueleiz S, Tedeschi A, et al. Combined fludarabine, cyclophosphamide, and alemtuzumab (FCC), an active regimen for treated patients with chronic lymphocytic leukemia (CLL). Blood. 2007;110(11):3133.

71. Lepretre S, Aurran T, Mahe B, et al. Immunochemotherapy with fludarabine (F), cyclophosphamide (C), and rituximab (R) (FCR) versus fludarabine (F), cyclophosphamide (C) and mabcampath (Cam) (FCCam) in previously untreated patients (pts) with advanced B-chronic lymphocytic leukemia (B-CLL) : experience on safety and efficacy within a randomised multicenter phase III trial of the French Cooperative Group On CLL and WM (FCGCLL/MW) and the "Groupe Ouest-Est d'Etudes Des Leucémies Aigües Et Autres Maladies Du sang" (GOELAMS): CLL2007FMP (for fit medically patients). Blood. 2009; 114:538.

72. Clarke AR, Purdie CA, Harrison DJ, et al. Thymocyte apoptosis induced by 553 -dependent and independent pathways. Nature. 1993;362(6423):849-852.

73. Pettitt AR, Matutes E, Dearden C, et al. Results of the phase II NCRI CLL206 trial of alemtuzumab in combination with high-dose methylprednisolone for high-risk (17p-) CLL. Haematologica. 2009;94(Suppl 2):138 abstr. 0351.

74. Wierda WG, Obrien S, Ferrajoli A, et al. Salvage therapy with combined cyclophosphamide (C), fludarabine (F), alemtuzumab (A), and rituximab (R) (CFAR) for heavily pre-treated patients with CLL. Blood. 2005;106(11):719.

75. Wierda WG, O'Brien S, Faderl S, et al. Combined cyclophosphamide, fludarabine, alemtuzumab, and rituximab (CFAR), an active regimen for heavily treated patients with CLL. Blood. 2006;108(11):31.

76. Parikh SA, Keating M, O'Brien S, et al. Frontline combined chemoimmunotherapy with fludarabine, cyclophosphamide, alemtuzumab and rituximab (CFAR) in high-risk chronic lymphocytic leukemia. Blood. 2009; $114: 208$.

77. Frankfurt O, Hamilton E, Duffey S, et al. Alemtuzumab and rituximab combination therapy for patients with untreated CLL - a phase II trial. Blood. 2008;112(11):2098.

78. Zent CS, Call TG, Shanafelt TD, et al. Early treatment of high-risk chronic lymphocytic leukemia with alemtuzumab and rituximab. Cancer. 2008;113(8):2110-2118.

79. Dyer MJ, Kelsey SM, Mackay HJ, et al. In vivo, purging' of residual disease in CLL with Campath-1H. Br J Haematol. 1997;97(3): 669-672.

80. O'Brien SM, Kantarjian HM, Thomas DA, et al. Alemtuzumab as treatment for residual disease after chemotherapy in patients with chronic lymphocytic leukemia. Cancer. 2003;98(12): 2657-2663.

81. Wierda WG, Kipps TJ, Keating MJ, et al. Self-Administered, subcutaneous (SQ) alemtuzumab to eliminate residual disease in patients (pts) with CLL. Blood. 2006;108(11):2839.

82. Schweighofer CD, Ritgen M, Eichhorst BF, et al. Consolidation with alemtuzumab improves progression-free survival in patients with chronic lymphocytic leukaemia (CLL) in first remission: long-term follow-up of a randomized phase III trial of the German CLL Study Group (GCLLSG). Br J Haematol. 2009;144(1):95-98.

83. Wendtner CM, Ritgen M, Schweighofer CD, et al; Consolidation with alemtuzumab in patients with chronic lymphocytic leukemia (CLL) in first remission - experience on safety and efficacy within a randomized multicenter phase III trial of the German CLL Study Group (GCLLSG). Leukemia. 2004;18(6):1093-1101. 
84. Fischer K, Schweighofer CD, Ritgen M, et al; Dose escalation study to evaluate dose limiting toxicity (DLT), maximum tolerated dose (MTD) and safety of alemtuzumab for consolidation therapy in patients with chronic lymphoycytic leukemia: Phase I/II trial of the German CLL Study Group (GCLLSG). Blood. 2007;110(11):2053-.

85. Lin T, Donohue K, Lucas M, et al. Consolidation therapy with subcutaneous (SC) alemtuzumab results in severe infectious toxicity in previously untreated CLL patients who achieve a complete response (CR) after fludarabine and rituximab (FR) induction therapy: interim safety analysis of the CALGB Study 10101. Blood. 2007; 110(11):755.

86. Hainsworth JD, Vazquez ER, Spigel DR, et al. Combination therapy with fludarabine and rituximab followed by alemtuzumab in the firstline treatment of patients with chronic lymphocytic leukemia or small lymphocytic lymphoma: a phase 2 trial of the Minnie Pearl Cancer Research Network. Cancer. 2008;112(6):1288-1295.

87. Rai KR, Peterson BL, Appelbaum FR, et al. Fludarabine compared with chlorambucil as primary therapy for chronic lymphocytic leukemia. N Engl J Med. 2000;343(24):1750-1757.

88. Eichhorst BF, Busch R, Hopfinger G, et al. Fludarabine plus cyclophosphamide versus fludarabine alone in first-line therapy of younger patients with chronic lymphocytic leukemia. Blood. 2006;107(3): 885-891.

89. Flinn IW, Neuberg DS, Grever MR, et al. Phase III trial of fludarabine plus cyclophosphamide compared with fludarabine for patients with previously untreated chronic lymphocytic leukemia: US Intergroup Trial E2997. J Clin Oncol. 2007;25(7):793-798.
90. Knauf WU, Lissichkov T, Aldaoud A, et al. Phase III randomized study of bendamustine compared with chlorambucil in previously untreated patients with chronic lymphocytic leukemia. J Clin Oncol. 2009;27(26):4378-4384.

91. Robak T, Blonski JZ, Gora-Tybor J, et al. Cladribine alone and in combination with cyclophosphamide or cyclophosphamide plus mitoxantrone in the treatment of progressive chronic lymphocytic leukemia: report of a prospective, multicenter, randomized trial of the Polish Adult Leukemia Group (PALG CLL2). Blood. 2006;108(2):473-479.

92. Robak T, Blonski JZ, Kasznicki M, et al. Comparison of cladribine plus prednisone with chlorambucil plus prednisone in patients with chronic lymphocytic leukemia. Final report of the Polish Adult Leukemia Group (PALG CLL1). Med Sci Monit. 2005;11(10):PI71-PI79.

93. Hainsworth JD, Litchy S, Barton JH, et al. Single-agent rituximab as first-line and maintenance treatment for patients with chronic lymphocytic leukemia or small lymphocytic lymphoma: a phase II trial of the Minnie Pearl Cancer Research Network. J Clin Oncol. 2003;21(9):1746-1751.

94. Cheson BD, Bennett JM, Grever M, et al. National cancer institutesponsored working group guidelines for chronic lymphocytic leukemia: revised guidelines for diagnosis and treatment. Blood. 1996;87(12):4990-4997.
OncoTargets and Therapy

\section{Publish your work in this journal}

OncoTargets and Therapy is an international, peer-reviewed, open access journal focusing on the pathological basis of all cancers, potential targets for therapy and treatment protocols employed to improve the management of cancer patients. The journal also focuses on the impact of management programs and new therapeutic agents and protocols on

\section{Dovepress}

patient perspectives such as quality of life, adherence and satisfaction. The manuscript management system is completely online and includes a very quick and fair peer-review system, which is all easy to use. Visit http://www.dovepress.com/testimonials.php to read real quotes from published authors. 